\title{
Oral health knowledge, attitudes and practices among school teachers in Tshwane district, South Africa
}

SADJ June 2021, Vol. 76 No. 5 p250 - p255

T Mfolo', TK Madiba², A Bhayat ${ }^{3}$

\section{ABSTRACT}

\section{Introduction}

Teachers are perceived as role models and studies have shown that they can enhance the oral health behaviour of young children.

\section{Aims and objectives}

To assess the oral health $(\mathrm{OH})$ knowledge, attitudes and practices of public school teachers in a district in Pretoria, South Africa.

\section{Methods}

This was a cross sectional analytical study. The sample comprised of six schools that were randomly selected within the Tshwane West sub district. A total of 160 teachers were included. A modified, self-administered, validated questionnaire was used to obtain the data.

\section{Results}

Of the 160 teachers included, 97 (61\%) completed the questionnaire. The majority $(80 \%)$ were female and the mean age was 38.23 years $( \pm 12.85 ; 22-66)$. More than $80 \%$ had an adequate level of $\mathrm{OH}$ knowledge, 94\% reported it was important to visit a dental practitioner (DP) regularly and $94 \%$ believed that $\mathrm{OH}$ education should form part of the teaching curriculum. The most common reason for visiting a DP was toothache (32\%) while fear (35\%) was the most common barrier.

\section{Author affiliations:}

1. Tshepiso Mfolo: BChD (UWC), PG Dip Dent (Aesthetic Dent), PG Dip Dent (Comm Dent), MSc Dent (UP), Faculty of Health Sciences, School of Dentistry-Department of Community Dentistry, University of Pretoria, Pretoria, South Africa. ORCID Number: 0000-0003-1710-6840

2. Thomas K Madiba: B. Dent Ther, BDS, DHSM, MChD (UP), Faculty of Health Sciences, School of Dentistry-Department of Community Dentistry, University of Pretoria, Pretoria, South Africa. ORCID Number: 0000-0002-0171-0595

3. Ahmed Bhayat: BDS, MSc, MPH, M Dent (WITS), Faculty of Health Sciences, School of Dentistry Department of Community Dentistry, University of Pretoria, Pretoria, South Africa.

ORCID Number: 000-0002-8103-1233

Corresponding author: Tshepiso Mfolo

Faculty of Health Sciences, School of Dentistry, Oral \& Dental Hospital, Department of Community Dentistry, University of Pretoria, Pretoria 0001, South Africa.

Email: tshepiso.mfolo@up.ac.za

Author contributions:

1. Tshepiso Mfolo: Principal author: data collection, scientific writing, proof reading manuscript - $40 \%$

2. Thomas K Madiba: Second author: scientific writing, proof reading manuscript - $35 \%$

3. Ahmed Bhayat: Third author: data analysis, proof reading manuscript - $25 \%$
Those with a higher mean age were more likely to brush frequently $(p<0.01)$, utilise dental aids $(p=0.01)$ and visit a DP regularly $(p=0.02)$.

\section{Conclusion}

The majority of teachers had adequate $\mathrm{OH}$ knowledge. The respondents with a higher mean age were more likely to brush frequently, use dental aids and visit a DP regularly.

Workshops for teachers are required to improve current levels of knowledge and address any queries regarding prevention and diagnosing of dental diseases.

\section{Keywords}

Oral health, learners, knowledge, school teachers, attitudes, practices.

\section{INTRODUCTION}

Children spend most of the time with teachers throughout their school years in which much of their knowledge and skills are developed. ${ }^{1}$ Teachers are perceived as role models and studies have shown that teachers can enhance the dental health behaviour of young children. ${ }^{1-3}$ It is therefore important to determine the oral health $(\mathrm{OH})$ knowledge, attitude and practice of teachers in order to ensure that they provide appropriate and accurate $\mathrm{OH}$ information to their learners. Studies have reported that teachers with good $\mathrm{OH}$ knowledge are more confident in teaching young children about their $\mathrm{OH}$ compared to those with poor knowledge. . $6^{4}$

Many studies carried out among future and current school teachers reported that their oral health knowledge was mostly insufficient and inaccurate. ${ }^{6-9}$ The teachers' insufficient knowledge and lack of skills and motivation to offer $\mathrm{OH}$ education showed possible adverse consequences on learners' oral health. ${ }^{7}$

Schools provide an important setting for promoting good health by allowing learners to develop lifelong sustainable attitudes and skills. ${ }^{10}$ It is essential to provide $\mathrm{OH}$ education in schools and it is considered to be easily integrated into general health promotion, school curricula and activities. ${ }^{11}$ If teachers have sufficient $\mathrm{OH}$ knowledge, they could act as role models and sustain the schools' brushing and rinsing programmes. Dental health affects general health, well- 
being, education and development of children. ${ }^{11}$ Children suffering from dental caries (DC) and other $\mathrm{OH}$ problems have shown adverse effects in their development and participation in essential life activities. ${ }^{11}$ The presence of oral pain and infection can limit food intake, consequently affecting the learners' growth, learning, communication skills and recreational activities. ${ }^{12}$

Children with oral diseases were more likely not to participate in normal activities and miss school hours compared to those without oral diseases. ${ }^{11}$ A study has reported that more than 50 million school hours can be lost annually as a result of oral diseases which can affect learners' performance at school and success in later life. ${ }^{13}$ Hence, the prevention of oral diseases at an early age could lead to a reduction in the initiation of systemic conditions, decrease the number of days lost from school and improve the general quality of life.

Limited studies have been conducted in South Africa to determine the $\mathrm{OH}$ knowledge, attitudes and practices of primary school teachers. The results from this study can help identify gaps in their knowledge in order for appropriate workshops to be conducted. The workshops can possibly improve their current knowledge and identify challenges faced by the teachers when implementing school brushing programmes.

The aim was to assess the $\mathrm{OH}$ knowledge, attitudes and practices of primary school teachers in Pretoria, South Africa.

\section{MATERIALS AND METHODS}

A cross sectional analytical study design was used. A cluster sampling technique was used to obtain the necessary sample of teachers. The study was conducted during February to March 2018. A list of all public primary schools in the Tshwane area were identified and due to time and financial constraints, only schools in sub district Tshwane West were selected. There were 86 schools in this sub district and each of them had an average of 30 teachers. In total there were 2580 teachers and with a confidence level of $95 \%$ and margin of error of $10 \%$, a minimum of 93 teachers were required.

Six schools were randomly selected in order to obtain the minimum sample of 93 . There were a total of 160 teachers employed at these schools and all of them were included in the study sample. Inclusion criteria compromised of all full-time primary teachers from the foundation phase to the intermediate phase (Grade 1 to Grade 7). All part time and student teachers, administrative staff and the principal were excluded from the study.

The data was collected using a modified self-administered questionnaire that was based on a previously validated questionnaire. ${ }^{1}$ The original questionnaire was prevalidated hence no validity tests were done. ${ }^{1}$ The questionnaire was paper based and in the English language. It was distributed to the teachers during school hours and consisted of four sections; demographic information (5 questions), knowledge (14 questions), attitudes (5 questions) and practice (6 questions) patterns of teach- ers towards oral health. There was one open- ended knowledge question namely: "What do you think caused the teeth to get rotten?" The questionnaire was anonymous and confidential. It was hand delivered to the principal of each school who then distributed it to the teachers. The completed forms were collected after one week. Written consent was obtained from each participant who signed the cover letter detailing the rationale for the study. Ethical clearance was obtained from the Faculty of Health Sciences Research Ethics Committee, the ethics clearance number is $245 / 2016$.

The knowledge score was calculated by the sum of each knowledge based question which was scored either one (1) if correct or zero (0) if incorrect. The maximum amount of correct answers were 16 and a score of $75 \%$ or more was classified as "adequate" while a score below $74 \%$ was classified as "inadequate". The open-ended knowledge question responses were grouped according to themes and reported accordingly.

The attitudes and practice responses were classified as either "yes", "no" or "I don't know" Their attitudes were obtained through questions such as importance of dental visits, willingness to teach $\mathrm{OH}$ education to learners and whether it should be introduced into the teaching curriculum.

The $\mathrm{OH}$ practices of teachers was obtained by asking questions related to the reasons and frequency of dental visits, brushing frequency and oral hygiene aids used for maintaining good oral hygiene.

Data was entered into Microsoft Office Excel spreadsheets, after which, it was checked for completeness, duplicates and for missing values. Once verified to be complete, the data was exported to the Statistical Package for Social Science software, SPSS ver.25. Quantitative variables were summarized as proportions, frequencies and means with standard deviations, range and percentages. The Chi square and ANOVA tests were used to evaluate the association between variables and the mean scores. The level of significance was set at $\mathrm{P}<$ 0.05. The study received ethics clearance from the Research Ethics Committee.

\section{RESULTS}

Out of the 160 teachers invited to participate, 97 (61\%) completed the questionnaire and were included in the study. The majority (80\%) were female and the mean age was 38.23 years $( \pm 12.85 ; 22-66)$. Only 87 respondents recorded their age and were included in the associations between age and other variables.

\section{Knowledge}

The majority of respondents answered the questions correctly (Table 1). More than two-thirds (84\%) had a score of $75 \%$ or more and were classified as having an "adequate" level of $\mathrm{OH}$ knowledge. Although not statistically significant $(P=0.15)$, teachers who obtained "adequate" knowledge score $(\geq 75 \%)$ were generally older (38.7 years) compared to those who obtained a "inadequate" (<75\%) knowledge score (33.4 years). 
For the open-ended qualitative question that sought to find causes of "rotten" teeth, three themes were identified. The authors agreed to these themes after examining the responses. Only seventy-eight responded to the question which meant that 19 (24\%) probably did not know the right answer. Out of the seventy eight that responded, twenty nine (37\%) responded that the cause of dental caries was a combination of dietary factors such as sweetened diets including drinks and poor oral hygiene practices (Theme 1). Thirty-eight (49\%) explained that the cause of dental caries is poor oral hygiene practices (Theme 2) whilst eleven (14\%) indicated that the cause of dental caries was poor diet including sugar sweetened beverages (Theme 3).

\section{Attitudes}

The majority (94\%) of respondents felt it was important to visit a dental practitioner (DP) regularly; $88 \%$ indicated that they were willing to teach learners about $\mathrm{OH}$ while 94\% felt that $\mathrm{OH}$ education should form part of the curriculum (Table 2). Of those who felt that $\mathrm{OH}$ should not be taught at school, more than half (53\%) cited lack of time as a barrier while $42 \%$ felt that they had inadequate knowledge which deterred them from teaching $\mathrm{OH}$ education.

\section{Practices}

A third of the respondents (35\%) claimed to visit the DP annually and $25 \%$ reported to only visit a DP when in pain (Table III). The most common reasons for visiting a DP were toothache (32\%) and sensitive teeth (13\%).

The majority of teachers reported to have not visited a DP due to fear (35\%) and the high cost of dental treatment (32\%) (Table 3). More than half (53\%) confirmed that their DP spoke to them about prevention of dental diseases at their last visit. The majority of respondents (83\%) reported brushing twice a day with 33\% reporting to use toothbrush, toothpaste, floss and a mouth rinse.

Approximately two-thirds of the participants (66\%) reported to brush both morning and evening and 14\% brushed only in the mornings. Almost half of the teachers $(47 \%)$ reported to be replacing their toothbrush every three months and 29\% reported to replace their tooth brush every six months. There was a positive correlation $(P<0.01)$ between those who received preventive information from their DP and the need for the inclusion of $\mathrm{OH}$ education into the teaching curriculum.

Table 4 displays the associations between the mean age and $\mathrm{OH}$ practices. Those with a higher mean age were inclined to brush more frequently $(P<0.01)$, use a toothpick more often to clean their teeth $(P=0.01)$ and visited a DP more regularly $(P=0.02)$ compared to their colleagues with a lower mean age. The number of respondents included in the association between age and oral health practices (87) were much lower than those reported in Table 3 (93). This was due to the fact that not all respondents included their age and as such, when performing the statistical test, these were excluded.

\section{DISCUSSION}

More than $70 \%$ of the respondents had adequate knowledge concerning $\mathrm{OH}$ and this was much higher than other similar studies in India, where the teacher's level of knowledge was reported to be between $44 \%$ and $56 \% .{ }^{14,15}$ In a study conducted in Tanzania, the knowledge of teachers was reported to be $50 \%{ }^{6}$

The fact that teachers in this study had adequate knowledge is encouraging as these teachers play an important role as role models to the learners. It was also interesting to note that older teachers had more knowledge than younger teachers and this might be due to the fact that they had experienced dental problems in their lives and might also have been exposed to dental education.

The finding is similar to a study done by Shodan et al., which showed that experienced teachers had more knowledge as they might have gained knowledge through years of teaching experience. ${ }^{16}$ In an open-ended qualitative question, only twenty nine (37\%) had a correct answer for the causes of dental caries which was that dental caries had a multifactorial aetiology (complex of "bacteria + sugar"). The majority of teachers (49\%) exhibited knowledge of the role of bacteria in caries aetiology, and very few (14\%) of them were aware that high

\begin{tabular}{|c|c|c|}
\hline Knowledge item & Correct answers - $\mathrm{n}(\%)$ & Incorrect answer - $\mathbf{n}(\%)$ \\
\hline 1. What do you think can cause bleeding gums? & $96(99)$ & $1(1)$ \\
\hline 2. How can you protect yourself from gum disease? & $90(93)$ & $7(7)$ \\
\hline 3. What is dental plaque? & $67(69)$ & $30(31)$ \\
\hline 4. What is calculus? & $49(51)$ & $48(49)$ \\
\hline 5. What can dental plaque cause? & $89(92)$ & $8(8)$ \\
\hline 6. Can eating sweets cause dental problems? & $95(98)$ & $2(2)$ \\
\hline 7. Can drinking soft drinks (Coke, Fanta, etc) cause dental problems? & $95(98)$ & $2(2)$ \\
\hline 8. Does the health of mouth and teeth impact on the health of the body? & $94(97)$ & $3(3)$ \\
\hline 9. Do you think we need to treat tooth pain and bleeding gums? & 96 (99) & $1(1)$ \\
\hline 10. Does brushing and cleaning your teeth regularly prevent rotten teeth? & $95(98)$ & $2(2)$ \\
\hline 11. Does your current toothpaste contain fluoride? & $82(85)$ & $15(15)$ \\
\hline 12. What does fluoride in toothpastes do for your teeth? & $90(93)$ & $7(7)$ \\
\hline 13. Does using a tooth brush help to prevent gum disease? & $87(90)$ & $10(10)$ \\
\hline 14. Does using dental floss help prevent gum disease? & $88(91)$ & $9(9)$ \\
\hline
\end{tabular}


Table 2. Attitudes of teachers about oral health $(n=97)$.

\begin{tabular}{|c|c|c|c|}
\hline Attitudes & Yes - n (\%) & No - n (\%) & I Don’t Know - n (\%) \\
\hline Are regular visits to the dentist necessary $(n=96)$ & $90(94)$ & $6(6)$ & $0(0)$ \\
\hline Introducing oral health into the school curriculum $(n=97)$ & $91(94)$ & $4(4)$ & $2(2)$ \\
\hline Are you willing to teach learners about oral health and brushing techniques? $(n=95)$ & $84(88)$ & $9(9)$ & $2(3)$ \\
\hline \multicolumn{4}{|l|}{ Reasons for not willing to teach learners about oral health in the school curriculum $(n=9)$} \\
\hline Lack of time $(n=5)$ & $53 \%$ & & \\
\hline Inadequate knowledge $(n=3)$ & $42 \%$ & & \\
\hline Not interested $(n=1)$ & $5 \%$ & & \\
\hline It's not important $(n=0)$ & 0 & & \\
\hline
\end{tabular}

\begin{tabular}{|c|c|}
\hline Frequency of DP visits $(n=92)$ & $N^{*}(\%)$ \\
\hline Once a year & $32(35)$ \\
\hline Twice a year & $23(25)$ \\
\hline When in pain & $23(25)$ \\
\hline Occasionally & $14(15)$ \\
\hline \multicolumn{2}{|l|}{ Reasons for the last visit $(n=93)$} \\
\hline Toothache & $30(32)$ \\
\hline Sensitive teeth & $12(13)$ \\
\hline Dentist advice & $10(11)$ \\
\hline Others (check-up, halitosis, gingivitis, advice from friends and family) & $41(44)$ \\
\hline \multicolumn{2}{|l|}{ Reasons for not visiting a DP $(n=92)$} \\
\hline Fear of dental treatment & $32(35)$ \\
\hline High cost of dental treatment & $29(32)$ \\
\hline No reason & $20(22)$ \\
\hline No time & 11(11) \\
\hline \multicolumn{2}{|l|}{ Frequency of brushing $(n=93)$} \\
\hline Once daily & $10(11)$ \\
\hline Twice daily & $77(83)$ \\
\hline More than two times & $6(6)$ \\
\hline \multicolumn{2}{|l|}{ What aids do you use to maintain good oral health $(n=93)$} \\
\hline Toothbrush and paste & $26(28)$ \\
\hline Toothbrush, paste and mouthwash & 11(12) \\
\hline Toothbrush, paste and floss & $20(22)$ \\
\hline Toothbrush, paste, floss and mouthwash & $31(33)$ \\
\hline Others & $5(5)$ \\
\hline \multicolumn{2}{|l|}{ What aids do you use to maintain good oral health $(n=93)$} \\
\hline Every month & $9(9)$ \\
\hline Every 3 months & $44(47)$ \\
\hline Every 6 months & $27(29)$ \\
\hline Annually & $6(7)$ \\
\hline When its worn out & $7(8)$ \\
\hline
\end{tabular}

\begin{tabular}{|c|c|c|c|}
\hline Daily frequency of brushing $\left(n=87^{* *}\right)$ & $\mathbf{N}$ & Mean age & P value* \\
\hline Once & 10 & 32.00 & \multirow{3}{*}{$<0.01$} \\
\hline Twice & 72 & 37.82 & \\
\hline More than two times & 5 & 53.60 & \\
\hline \multicolumn{4}{|l|}{ Method of cleaning $\left(n=75^{\star *}\right)$} \\
\hline Toothbrush and paste & 25 & 37.36 & \multirow{4}{*}{0.01} \\
\hline Toothbrush, paste and floss & 17 & 34.94 & \\
\hline Toothbrush, paste, floss and mouthwash & 28 & 38.29 & \\
\hline Toothbrush, paste, floss and toothpick & 5 & 59.83 & \\
\hline \multicolumn{4}{|l|}{ Frequency of dental visits $\left(\mathrm{n}=85^{\star \star}\right)$} \\
\hline Once per year & 31 & 39.87 & \multirow{4}{*}{0.02} \\
\hline Twice per year & 19 & 43.84 & \\
\hline When in pain & 23 & 36.88 & \\
\hline Occasionally & 12 & 30.08 & \\
\hline
\end{tabular}


level of sugar consumption can cause dental caries. This is in contrast with the studies done by Sekhar $V$ et al., Verma et al., and Khan et al where the majority of the study participants had knowledge regarding causes of dental caries i.e. bacteria + sugar complex. . $^{2,17,18}$

The findings of this study are concerning and indicative of the gaps in knowledge and the need to conduct oral health workshops for the teachers, to thoroughly explain the cause of dental caries. This will in turn, empower the teachers to disseminate correct information to their learners.

Twenty three (25\%) reported to have visited a DP only when in pain; this was lower than a similar study that reported that $38 \%$ of teachers visited a DP when they had pain. ${ }^{15}$ A vast majority of teachers (94\%) felt it was important to visit a DP regularly and this was higher than similar studies. 2,19 The results of this study are encouraging as it shows that the teachers realized the role that DP play in the prevention of oral diseases.

It was interesting to note that the teachers with a higher mean age were more likely to brush their teeth and visit a DP more frequently compared to those with a lower mean age. These results are similar to a study conducted in Saudi Arabia where older teachers, with more experience, believed in brushing more frequently and visiting the DPs regularly. ${ }^{20}$

In general, these teachers with a higher mean age had more knowledge about $\mathrm{OH}$ diseases than their counterparts with a lower mean age. The younger teachers could have had less exposure about oral health education compared to the older teachers. The older teachers are more likely to have children and grandchildren; therefore, they might have taken them to the DPs, as a result giving them more exposure to oral health information. This finding suggests that when offering oral health education messages in schools, special emphasis should be placed on younger teachers to inform them of the danger of neglecting oral health.

This study's findings should be interpreted with caution, as there are some study design limitations. For example, this was a cross-sectional study; therefore, causality cannot be inferred. Although the minimum sample size of 93 was reached, the response rate of $61 \%$ was considered low and this could be due to the fact that the questionnaires were left at schools to be collected later or due to a lack of time or interest.

The majority of teachers were female (80\%), this is similar to the studies done by Sekhar $\mathrm{V}$ et al. in Pondicherry and Verma et al. in Faridabad, where most of the study subjects were female i.e. $79 \%$ and $80 \%$ respectively. ${ }^{2,17}$ This might have been due to gender differences in jobrelated preferences and societal roles. This might have a positive input in disseminating $\mathrm{OH}$ messages to the learners, as females are generally primary caregivers. Response acquiescence is common among questionnaires that tend to determine habits that are considered taboo or have negative connotations. There was no oral examination conducted to verify the $\mathrm{OH}$ status of these teachers and to corroborate their responses.
The majority of teachers reported to have an acceptable level of $\mathrm{OH}$ knowledge. Almost half reported to visit a DP regularly and agreed on the importance of including $\mathrm{OH}$ into the teaching of young children. This was an important finding as it showed that teachers realised the importance of good oral health and were willing to include it into the teaching curriculum. Meetings and workshops should be arranged between teachers and oral health workers to improve their knowledge by providing oral health infographics and posters. These teaching aids can assist in spreading oral health information amongst both teachers and learners.

The most common reason for visiting a DP was toothache and the most common barrier to dental care was fear. This shows that teachers did not visit dentists or oral health care workers for prevention and only when in pain. Additional information must be shared with the teachers highlighting the importance of prevention in dental care compared to curative care. The high levels of fear preventing access to dental care could be the reason why these participants stated they only visited a dentist when in pain.

\section{CONCLUSION}

Although the knowledge, attitudes and practices were adequate, gaps were identified and workshops should be implemented in order to improve the existing levels of $\mathrm{OH}$ knowledge amongst this cohort of teachers. Teachers should be allowed more time for including $\mathrm{OH}$ into their teaching curriculum.

\section{Financial support and sponsorship}

Nil.

\section{Publication}

No prior or duplicate submission of the manuscript has been made elsewhere of any part of the work.

\section{Conflicts of interest}

There are no conflicts of interest.

The manuscript has been read and approved by all the authors. The requirements of authorship have been met and each author believes that the manuscript represents honest work.

\section{Clinical significance}

This study is essential when considering the role that teachers play in the development of young children. If the teachers can impart good oral hygiene practices to young children, it will have an impact on their oral and general heath in their future and the future of the next generation.

This study identified gaps in the oral health knowledge of teachers. As a result, workshops will be planned by our staff members for all the teachers in these schools to improve their current levels of knowledge and answer any queries they may have regarding the prevention and identifying of dental diseases. 


\section{References}

1. Manjunath G, Kumar N. Oral Health Knowledge, Attitude and Practices Among School Teachers in Kurnool - Andhra Pradesh. Journal of Oral Health \& Community Dentistry. 2013; 7(1): 17-21.

2. Sekhar V, Sivsankar P, Easwaran M, Subitha L, Bharath $\mathrm{N}$, Rajeswary K, et al. Knowledge, attitude and practice of school teachers towards oral health in Pondicherry. J Clin Diagn Res. 2014; 8(8): ZC12ZC15.

3. Thomas S, Tandon S, Nair S. Effect of dental health education on the oral health status of a rural child population by involving target groups. J Indian Soc Pedod Prev Dent. 2000; 18(3): 115-25.

4. Aljanakh M, Siddiqui AA, Mirza AJ. Teachers' knowledge about oral health and their interest in oral health education in Hail, Saudi Arabia. Int J Health Sci (Qassim). 2016; 10(1): 87-93.

5. Glasrud PH, Frazier PJ. Future elementary schoolteachers' knowledge and opinions about oral health and community programs. J Public Health Dent. 1988; 48(2): 74-80.

6. Mwangosi IE, Nyandindi U. Oral health related knowledge, behavious,attitude and self-assessed statusof primary school teachers in Tanzania. Int Dent J. 2002; 52(3): 130-6

7. Åstrøm AN, Jackson W, Mwangosi IEt. Knowledge, beliefs and behavior related to oral health among Tanzanian and Ugandan teacher trainees. Acta Odontologica. 2000; 58(1): 11-8.

8. Sequeira D, Peter S, Rao A, Kundabala M. Dental awareness among Kannada and English Medium Primary school teachers in Mangalore city. J Indian Asso Public Health Dent. 2006; 4(7): 7-12

9. Lang P, Woolfolk MW, Faja BW. Oral health knowledge and attitudes of elementary schoolteachers in Michigan. J Public Health Dent. 1989; 49(1): 44-50

10. Al-Ansari DSS. Preventive oral health programmes at schoo health (MOE) Prospective of a new collaboration. Saudi Dental Journal. 2007; 19: 018.

11. Kwan SY, Petersen PE, Pine CM, Borutta A. Health-promoting schools: an opportunity for oral health promotion. Bull World Health Organ. 2005; 83(9): 677-85.

12. Sharma V, Amith HV, Bhambal A, Rai KS, Rai P, Sharma A Knowledge, Attitude and Practice Regarding Oral Health among Primary School Teachers of Bhopal City Central India. Int J Sci Stud. 2015; 3(1): 54-7

13. Jackson SL, Vann WF, Kotch JB. Impact of Poor Oral Health on Children's School Attendance and Performance. Am J Public Health. 2011; 101(10): 1900-6.

14. Haloi R, Ingle NA, Kaur N, Gupta R. Comparing the oral health promoting role and knowledge of government and private primary school teachers in Mathura city. Int J Sci Study. 2014; 1: $9-14$

15. Jagan $\mathrm{P}$, Fareed N, Battur H, Khanagar S, Bhat M. Conceptual knowledge of oral health among school teachers in South India, India. Eur J Dent. 2018; 12(1): 43-8

16. Shodan M, Prasad KW, Javali SB. School-Teachers Knowledge about Prevention of Dental Caries and Malocclusion in India. J Oral Health Comm Dent. 2014; 8(1): 6-11.

17. Verma N, Jain M, Yadav RN, Poudel S, Sharma A, Jain V. School Teacher's Knowledge, Attitude and Practices Regarding Oral Health in Ballabhgarh Block, Faridabad. Indian Journal of Public Health Research \& Development. 2019; 10(3): 169-71.

18. Khan N, Al-Shaafi M, Al-Garawi Z. Dental caries, fluorosis and knowledge of school teachers. Pakistan Oral and Dental Journal. 2000; 20: 52-62.

19. Purohit A, Nichlani G, Patil G, Rizvi F, Uikey G and Purohit BM. Oral Health Knowledge, Attitude and Practice among Indian Preschool Teachers. SM J Dent. 2016; 2(1): 1007.

20. Al Rasheed NM, Shetty AC. Oral health knowledge among female primary school teachers in Riyadh city, Kingdom of Saudi Arabia. IJADS. 2017; 3(4): 164-70. 